\title{
Mouthwash, Powder for Solution Dosage Form
}

National Cancer Institute

\section{Source}

National Cancer Institute. Mouthwash, Powder for Solution Dosage Form. NCI

Thesaurus. Code C149668.

Solid preparation consisting of one or more powders intended to be dissolved in the specified liquid to obtain a mouthwash. 